\title{
Definitive radiotherapy for early (T1-T2) Glottic Squamous cell carcinoma: a 20 year Cleveland clinic experience
}

\author{
Mohammad K Khan ${ }^{\text {* }}$, Shlomo A Koyfman², Grant K Hunter ${ }^{2}$, Chandana A Reddy ${ }^{2}$ and Jerrold P Saxton ${ }^{2}$
}

\begin{abstract}
Purpose: To report our $20 \mathrm{yr}$ experience of definitive radiotherapy for early glottic squamous cell carcinoma (SCC). Methods and materials: Radiation records of 141 patients were retrospectively evaluated for patient, tumor, and treatment characteristics. Cox proportional hazard models were used to perform univariate (UVA) and multivariate analyses (MVA). Cause specific survival (CSS) and overall survival (OS) were plotted using cumulative incidence and Kaplan-Meir curves, respectively.

Results: Of the $91 \%$ patients that presented with impaired voice, $73 \%$ noted significant improvement. Chronic laryngeal edema and dysphagia were noted in 18\% and 7\%, respectively. The five year LC was 94\% (T1a), 83\% (T1b), 87\% (T2a), 65\% (T2b); the ten year LC was 89\% (T1a), 83\% (T1 b), 87\% (T2a), and 53\% (T2b). The cumulative incidence of death due to larynx cancer at 10 yrs was 5.5\%, respectively. On MVA, T-stage, heavy alcohol consumption during treatment, and used of weighted fields were predictive for poor outcome $(p<0.05)$. The five year CSS and OS was $95.9 \%$ and $76.8 \%$, respectively.

Conclusions: Definitive radiotherapy provides excellent LC and CSS for early glottis carcinoma, with excellent voice preservation and minimal long term toxicity. Alternative management strategies should be pursued for T2b glottis carcinomas.
\end{abstract}

Keywords: Glottic carcinoma, Larynx, Outcome, Radiotherapy, Squamous cell, Carcinoma

\section{Introduction}

Several institutions have reported long term outcomes of patients with T1-2N0 SCC of the glottis treated with definitive radiotherapy[1-10]. The five-year local control (LC) rates have ranged from $82-94 \%$ for $\mathrm{T} 1 \mathrm{a}, 80-93 \%$ for T1b, $62-94 \%$ for T2a, and $23-73 \%$ for T2b. We report our first 20 year institutional outcome, and identify patient, tumor, and treatment related factors associated with inferior outcomes.

\section{Methods and materials}

We obtained institutional review board (IRB) approval to retrospectively review the charts of all patients treated with definitive radiotherapy at the Cleveland Clinic between 1986-2006. All patients had biopsy-proven

\footnotetext{
* Correspondence: drkhurram2000@gmail.com

'Winship Cancer Center, Emory University, Atlanta, GA, USA

Full list of author information is available at the end of the article
}

invasive SCC of the glottis, staged T1 or T2 with negative lymph node disease, and had received an uninterrupted course of radiotherapy. Patients were excluded if they previously had major surgery of the neck or the glottis, had a synchronous primary, or had received chemotherapy. Minor surgery (stripping for squamous cell carcinoma in-situ (SCIS) or minor cordotomy) was allowed. The AJCC $6^{\text {th }}$ edition [11] was used to stage all patients, but with further sub-classification of T2 patients. Patients were staged as follows: T1 included tumor confined to a single vocal cord (T1a) or both vocal cords (T1b) with normal vocal cord mobility; T2 included tumor with supra- or subglottic extension and further subdivided into T2a (without) or T2b (with) impaired vocal cord mobility.

All patients were treated with radiotherapy alone using either a unilateral field or a weighted opposed lateral field technique (Figure 1A). Standard field borders were

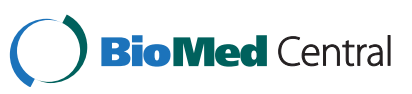




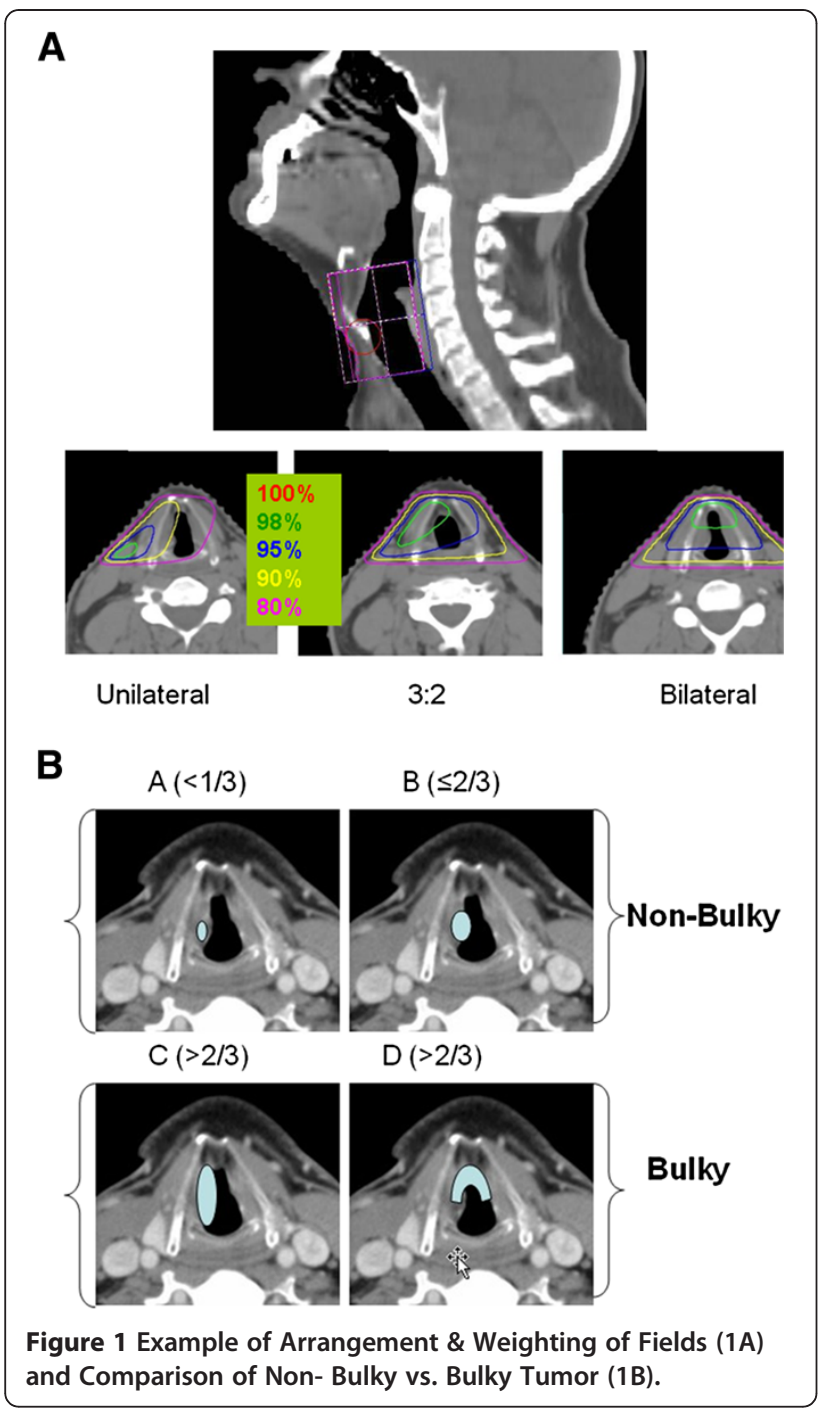

used in most cases for both techniques: 1) superior: mid thyroid notch; 2) inferior: bottom of cricoid cartilage; 3 ) posterior: $1 \mathrm{~cm}$ posterior to the thyroid cartilage but anterior to the vertebral body; 4) anterior: $1 \mathrm{~cm}$ anterior to the skin of the neck ("flash"). Most patients were treated using 5500 cGy (range 4400-6940 cGy) in 25 fractions of 220 cGy per fraction (range 180-225 cGy) using a larger field followed by a boost to a smaller volume "cone down" of 1320 cGy (range 600-2520 cGy) using 220 cGy per fraction (range 180-225 cGy) for a total dose of 6820 cGy (range 6300-7264) to the tumor. Higher radiation doses were reserved for patients with more bulky T2 tumors. Most patients underwent a cone down after $5500 \mathrm{cGy}$ where the posterior border was placed immediately posterior to the arytenoids, unless tumor extended to this region. Unilateral fields were used for unilateral and well localized tumors. Bilateral fields were used for all other tumors using one of three techniques depending on the relative distribution of the tumor across both vocal cords: equally weighted, weighted $2: 1$, or weighted $3: 2$. The neck nodes were treated only in cases where there was significant supragottic or sublgottic extension suggesting increased likelihood for subclinical nodal involvement. This methodology has been kept consistent over the 20 yrs of this study, and is part of the routine practice at our institution.

All statistical computations were performed using SAS version 9.2 (SAS Institute Inc., Cary, NC software. Local control (LC) and overall survival (OS) were plotted using the Kaplan-Meier method. The log-rank test was used to detect statistically significant differences among survival curves. Cause specific survival (CSS) was calculated using the cumulative incidence method. UVA and MVA analyses were performed via Cox regression analysis for the endpoint LC. The following parameters were included in the UVA: age, gender, race, smoking status, heavy alcohol consumption, tumor bulk (amount of cord involved), grade, histology, T-stage (T2 vs T1 and T2b vs all $\mathrm{T} 1 / \mathrm{T} 2 \mathrm{a}$ ), anterior commissure involvement, supraglottic/subglottic extension, daily dose $\leq 2 \mathrm{~Gy}$, total dose $\leq 66 \mathrm{~Gy}$, field weighting (unilateral vs. bilateral equally weighted vs. bilateral unequally weighted), and total treatment time. Tumor bulk was modeled as a continuous variable and classified as involvement of $>2 / 3$ of a cord involved by tumor (Figure 1B). Anterior commissure involvement with extension beyond $1 / 3$ of each cord was categorized as a bulky tumor (Figure 1B). This classification of tumor bulk is identical to that published by Reddy et al. [12] Total dose and treatment time were also modeled as continuous variables. Factors that were significant (p-value <0.05) in the UVA were then included in a MVA. Quality of life variables that were assessed to determine acute and late toxicity post radiation included: patient and physician reported voice quality pre- and post treatment, physician reported laryngeal edema as noted on direct laryngoscopy, patient reported symptomatic dysphagia requiring dilatations, pre and post treatment trismus, the need for salvage surgeries, and the patterns of failure.

\section{Results}

Patient, tumor and treatment related characteristics are depicted in Table 1, along with their association with local control on UVA. The mean follow-up time was 5.6 years. The mean age of the patients was 67 years. The median dose was 6820 cGy delivered at 212 cGy per fraction in 32 fractions over 45 days. On UVA, heavy alcohol use during radiation $(\mathrm{p}=.02)$, anterior commissure involvement $(\mathrm{p}=.05)$, stage $(\mathrm{p}=.02)$, total radiation dose $(\mathrm{p}=0.04)$, subglottic extension $(\mathrm{p}=.05)$, and field weighting ( $\mathrm{p}=0.01$ ) were predictive for poor local control. On MVA, concurrent heavy alcohol usage $(\mathrm{p}<0.01)$, stage T2b $(\mathrm{p}=.02)$, and field weighting $(\mathrm{p}=.025)$ were significant 
Table 1 Patient ( $n$ - 141) Characteristics and Univariate Analysis for Impact on Local Control

\begin{tabular}{|c|c|c|}
\hline Characteristic & $\begin{array}{l}\text { \# of Patients } \\
\text { (range or \%) }\end{array}$ & $p$ value \\
\hline Mean Age (yrs) at end of radiation & $67(33-94)$ & 0.9055 \\
\hline Gender & & 0.3902 \\
\hline male & $125(88.7 \%)$ & \\
\hline female & $16(11.3 \%)$ & \\
\hline Race & & 0.1133 \\
\hline Caucasian & 119 (84.4\%) & \\
\hline Non-caucasian & $22(15.6 \%)$ & \\
\hline Median Pack Years & $44(0-135)$ & 0.6769 \\
\hline Smoker & & 0.3530 \\
\hline Never & $12(8.5 \%)$ & \\
\hline Former & $92(65.2 \%)$ & \\
\hline Current & $32(22.7 \%)$ & 0.5568 \\
\hline Unknown & $5(3.5 \%)$ & \\
\hline Heavy Alchohol Use & & 0.0630 \\
\hline Never (Reference) & $89(63.1 \%)$ & \\
\hline Former & $21(14.9 \%)$ & 0.8836 \\
\hline Current & $19(13.5 \%)$ & $\underline{0.0222}$ \\
\hline Unknown & $12(8.5 \%)$ & \\
\hline Ant Commissure & & $\underline{0.0505}$ \\
\hline Involved & $71(50.3 \%)$ & \\
\hline Non Involved & $52(36.9 \%)$ & \\
\hline Unknown & $18(12.8 \%)$ & \\
\hline Tumor Bulk & & 0.6386 \\
\hline Bulky & $55(39 \%)$ & \\
\hline Non bulky & $86(61 \%)$ & \\
\hline Hemoglobin (g/dL) & 14.2 & \\
\hline Grade & & 0.6614 \\
\hline Well (Reference) & $43(30.5 \%)$ & \\
\hline Moderate & $57(40.4 \%)$ & 0.7192 \\
\hline Poor & $14(10 \%)$ & 0.3646 \\
\hline Unknown & $27(19.1 \%)$ & \\
\hline Stage (T2b vs T1a/b/2a) & & $\underline{0.0205}$ \\
\hline $1 a$ & $65(46 \%)$ & $\underline{0.0033}$ \\
\hline $1 \mathrm{~b}$ & $21(14.9 \%)$ & 0.1766 \\
\hline $2 \mathrm{a}$ & $29(20.6 \%)$ & 0.0621 \\
\hline 2b (Reference) & $25(17.7 \%)$ & \\
\hline Unknown & $1(1 \%)$ & \\
\hline Subglottic Ext & & $\underline{0.0505}$ \\
\hline Yes & $18(12.8 \%)$ & \\
\hline No & $96(68.1 \%)$ & \\
\hline Missing & $27(19.2 \%)$ & \\
\hline$\underline{\text { Supraglottic Ext }}$ & & 0.4668 \\
\hline Yes & $30(21.2 \%)$ & \\
\hline No & $87(61.7 \%)$ & \\
\hline
\end{tabular}

Table 1 Patient ( $n$ - 141) Characteristics and Univariate Analysis for Impact on Local Control (Continued)

\begin{tabular}{|c|c|c|}
\hline Missing & $24(17 \%)$ & \\
\hline Median Overall Treatment Time (wks) & $6.5(4-9.7)$ & \\
\hline Radiation Dose (cGy) as Continous & $6820(6300-7264)$ & $\underline{0.0367}$ \\
\hline$\leq 66$ Gy & 45 & \\
\hline$>66 \mathrm{~Gy}$ & 96 & \\
\hline Median Dose/Fraction & $212(176-256)$ & 0.1353 \\
\hline$\leq 2 \mathrm{~Gy} / \mathrm{fx}$ & $45(31.9 \%)$ & \\
\hline$>2 \mathrm{~Gy} / \mathrm{fx}$ & $95(67.4 \%)$ & \\
\hline missing & $1(1 \%)$ & \\
\hline Mean Follow-Up (month) & $67.7(0-239)$ & \\
\hline
\end{tabular}

for poor local control (Table 2). Unilateral fields $(\mathrm{p}<0.03)$ and equally-weighted bilateral fields $(\mathrm{p}<0.04)$ were associated with improved local control compared to bilateral unequally weighted fields. Bilateral equally weighted fields and unilateral fields were equally effective $(\mathrm{p}=0.95)$.

\section{Local control}

The 5-year actuarial local control rates were as follows: T1a, 94\%; T1b, 83\%; T2a , 87\%; T2b, 65\%. The 10-year actuarial local control rates were as follows: T1a, 89\%; T1b, 83\%; T2a, 87\%; T2b, 56\% (Figure 2A). A total of 18 patients $(12.7 \%)$ experienced local failures (Table 3). The most common site of local recurrence was at the initial site of the tumor (6) followed by elsewhere on the true glottis but not at the original site of the primary location (4).

Table 2 Multivariate Analysis for Impact on Local Control

\begin{tabular}{lccc}
\hline Variables & p-value & HR & $\begin{array}{c}\mathbf{9 5 \%} \text { Confidence } \\
\text { (LL, UL) }\end{array}$ \\
\hline Heavy Alcohol Use & $\mathbf{0 . 0 0 0 6}$ & & \\
\hline Current vs Never & $\mathbf{0 . 0 0 0 2}$ & 42.32 & $(5.7,309)$ \\
\hline Former vs Never & 0.4738 & 0.44 & $(0.05,4.2)$ \\
\hline Current vs Former & $\mathbf{0 . 0 0 1 6}$ & 116.00 & $(6.0,1656)$ \\
\hline Ant Commisure Inv (n vs y) & 0.0940 & 0.21 & $(0.03,1.31)$ \\
\hline TStage & $\mathbf{0 . 0 2 4}$ & & \\
\hline 2b vs 1a & $\mathbf{0 . 0 2 8 8}$ & 0.09 & $(0.01,0.78)$ \\
\hline 2b vs 1b & 0.2 & 5.76 & $(0.4,83.4)$ \\
\hline 2b vs 2a & 0.8 & 0.78 & $(0.12,5)$ \\
\hline Total Dose (continuous variable) & 0.246 & 1.00 & $(0.99,1.00)$ \\
\hline Field Weighting/Arrangement & $\mathbf{0 . 0 5 6 9}$ & & \\
\hline Bilateral (Weighted) vs Non & $\mathbf{0 . 0 0 2 7}$ & 11.36 & $(1.32,100)$ \\
\hline Bilateral (Weighted) vs Unilateral & $\mathbf{0 . 0 4 2 2}$ & 10.70 & $(1.09,100)$ \\
\hline Bilateral (Non-weighted) vs & 0.9473 & 0.93 & $(0.123,7.11)$ \\
\hline Unilateral & & & \\
\hline Subglottic Ext (n vs y) & 0.7468 & 0.74 & $(0.117,4.860)$ \\
\hline
\end{tabular}



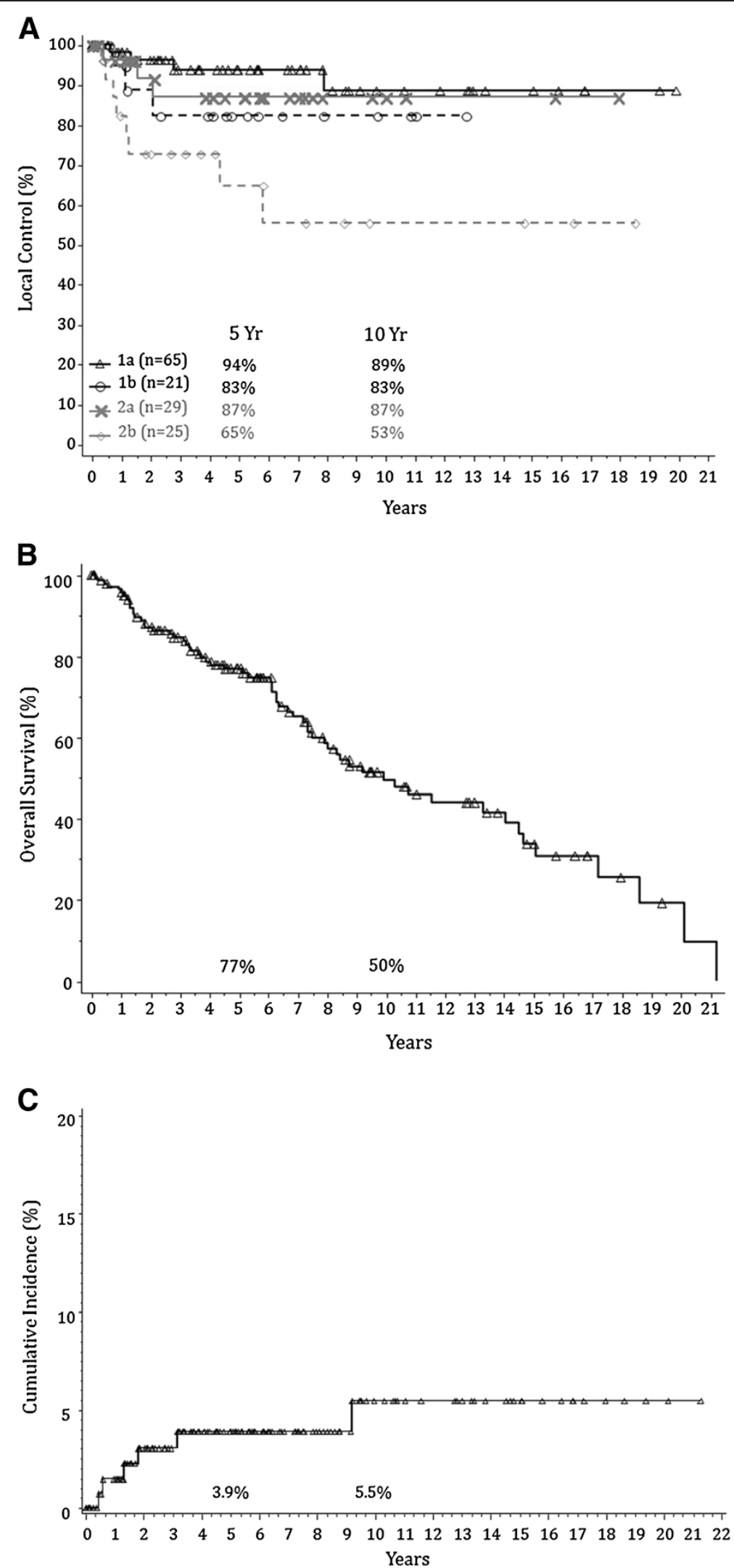

Figure 2 Outcomes Including Local Control Rate (Figure 2A), Overall Survival (Figure 2B), and Cumulative Incidence of Death (Figure 2C) For Early Glottic Carcinoma. 
Table 3 Outcomes Post Radiation Therapy

\begin{tabular}{lc}
\hline Outcomes Post Radiotherapy & n (\% of total) \\
\hline Local Recurrence & $18(12.8)$ \\
\hline Only at Primary Site & $6(4)$ \\
\hline Near Primary w/o Primary Site & $8(5.7)$ \\
\hline Loco-Regional Recurrenc Including Primary & $21(14.9)$ \\
\hline Nodal Failure Only w/o Primary & $3(2.1)$ \\
\hline Salvage Surgery & $20(14.2)$ \\
\hline Local Control with Salvage Sx & $135(95.7)$ \\
\hline Salvage w/o Functional Larynx & $11(7.8)$ \\
\hline Metastatic Failure & $3(2.1)$ \\
\hline Lower Tracheal/Stomal & $1(0.007)$ \\
\hline Lung & $1(0.007)$ \\
\hline Other Primary Cancers & $32(22.7)$ \\
\hline Most Common Site (Lung) & $9(6.3)$ \\
\hline
\end{tabular}

Neck control, metastatic failures, salvage therapy, and functional larynx

Neck control rates were $97.9 \%$ with only $3(2.1 \%)$ of the patients failing in the regional lymph nodes. Similarly, only 3 patients (2.1\%) developed non-regional metastatic failure: One in lower trachea and stoma, one in the lung, and one was unknown. The most common form of salvage therapy in 20 patients $(14.2 \%)$ was total laryngectomy (8), laser cordotomy (6), or subtotal laryngectomy (4). One patient had neither of these procedures and another only had selective lymph node dissection. Six of the patients that were salvaged underwent repeat salvage therapy with either subtotal laryngectomy (1), total laryngectomy (2) or some other procedure (3). The ultimate local control rate of all patients including those that were salvaged (12 out of 18 local failures) with surgery was $95.7 \%$. Of those that were salvaged 11 patients $(7.8 \%)$ were left without a functional larynx.

\section{Second tumors, overall survival, and cause specific survival}

Thirty-two patients (22.7\%) developed second cancers: the most common site was lung (9 patients) and prostate (2 patients). The 5 and 10-year overall survival rates were $77 \%$ and $50 \%$, respectively (Figure $2 \mathrm{~B}$ ). The 5 and 10 -year cumulative incidence of death were $3.9 \%$ and $5.5 \%$, respectively (Figure 2C). A total of 62 deaths (44\%) occurred over the study interval. Recurrent larynx cancer as the cause of death occurred in only 5 patients (3.5\%). The rest died of non-larynx and non-second cancer related causes (26 patients), other cancers (9 patients), or of unknown causes (22 patients). During the last follow-up, 78 patients $(55.3 \%)$ were alive without recurrent disease or were alive with recurrent disease (5 patients, $3.5 \%$ ).

\section{Voice quality and toxicity outcomes}

No patients experienced severe or fatal post radiation complications. Pre and post-treatment symptoms are shown in Table $4.92 \%$ were noted to have baseline impairment of voice prior to radiation. $73 \%$ of these patients reported significant improvement, while $8.5 \%$ noted chronic worsening of their voice. Chronic laryngeal edema was noted in 26 patients (18.4\%). Chronic dysphagia was noted in 9 patients $(6.4 \%)$. Only one patient $(0.7 \%)$ developed severe laryngeal edema requiring a tracheostomy (grade 4 ), and only one patient $(0.7 \%)$ developed severe dysphagia requiring long term tube feeding (grade 4).

\section{Discusion}

Our observed five-year LC for T1-T2a are excellent and are better than or comparable to others [10]. The slight

Table 4 Pre and Post Treatment Quality of Life

\begin{tabular}{|c|c|c|}
\hline & Number & (\%) \\
\hline \multicolumn{3}{|l|}{ Pre-Treatment } \\
\hline \multicolumn{3}{|l|}{ Voice Quality } \\
\hline Impaired & 129 & 91.5 \\
\hline Normal & 4 & 2.8 \\
\hline missing & 8 & 5.7 \\
\hline \multicolumn{3}{|l|}{ Trismus (pretx) } \\
\hline $\mathrm{N}$ & 123 & 87.2 \\
\hline Y & 2 & 1.4 \\
\hline missing & 16 & 11.3 \\
\hline
\end{tabular}

\begin{tabular}{|c|c|c|}
\hline Post Treatment & & \\
\hline \multicolumn{3}{|l|}{ Chronic Hoarseness } \\
\hline Improved & 103 & 73.0 \\
\hline Unchanged & 11 & 7.8 \\
\hline Worsened & 12 & 8.5 \\
\hline missing & 15 & 10.6 \\
\hline \multicolumn{3}{|l|}{ Trismus (posttx) } \\
\hline Improved & 1 & 0.7 \\
\hline None & 126 & 89.4 \\
\hline missing & 14 & 9.9 \\
\hline \multicolumn{3}{|l|}{ Chronic Laryngeal Edema } \\
\hline None & 101 & 71.6 \\
\hline Mild/Mod & 24 & 17.0 \\
\hline Severe & 1 & 0.7 \\
\hline Very Severe & 1 & 0.7 \\
\hline missing & 14 & 9.9 \\
\hline \multicolumn{3}{|l|}{ Chronic Dysphagia } \\
\hline None & 118 & 83.7 \\
\hline Mild & 7 & 5.0 \\
\hline Moderate & 1 & 0.7 \\
\hline Severe & 1 & 0.7 \\
\hline missing & 14 & 9.9 \\
\hline
\end{tabular}


differences in LC could be due to the fact that we included all patients in our study, including three patients with spindle cell variant histology. All three of these patients failed locally suggesting the need for more aggressive treatment in these patients. Another reason could be due to the fact that we used a lower daily fractional dose and avoided hyper-fractionationation. Despite these subtle differences, we did not find total dose or the fractional dose to be statistically significant on MVA. This finding taken together with excellent outcome for T1a patients suggests that current treatment policies could be improved by reducing the total radiation dose or avoiding hyper-fractionation in these patients.

The relatively poor outcomes of patients with T2b glottic carcinoma suggests that there are various degrees of impaired mobility which are not adequately assessed with existing methods. The impaired mobility is an indication of the extent of disease. Some of these patients maybe on the verge of being T3 lesions, which would suggest the need for more aggressive treatment strategies such as hyper-fractionation or the use of concurrent chemo-radiotherapy. Trotti [13] et al. reported a non-statistically significant improvement of $9 \%$ in LC at five years $(p=0.11)$ for the use of hyper-fractionation in T2N0 glottic cancer patients. Akimoto [14] et al. reported that concurrent chemoradiotherapy had a nonsignificant improvement in disease free survival of $91.8 \%$ at 5 years compared to $70.9 \%$ no chemotherapy. Nonoshita et al. [15] reported an impressive three-year local control of $95.4 \%$ with the use of concurrent tegafur. Another treatment approach may involve some sort of limited surgical resection combined with neoadjuvant or adjuvant chemoradiotherapy. This approach has yet to be tested in a randomized trial.

Our analysis identified tumor stage (especially T2b), concurrent heavy alcohol consumption, and field weighting as factors that adversely impacted local control. Anterior commissure involvement was also noted to be statistically significant on MVA when we compared T2 patients with $\mathrm{T} 1$ patients. Tumor stage $[3,7,9,10]$ and anterior commissure[3,8] involvement have also been reported by others to predict for poor local control. Other factors previously reported by others to poorly impact local control on multivariate analysis include: total dose $(<65$ Gy) [8]; overall treatment time[5,8] $(>41$ days[10]); poorly differentiated histology[10]; smaller fraction sizes[5,8,9] (<2Gy vs $>2$ Gy[6]); subglottic extension[6-8]; treatment delay ( $>3$ days)[2]; treatment interruptions[2]; age, smaller field sizes[2,9]; gender[3,7]; higher beam energy[3]; pre-treatment hemoglobin levels $[4,7]$; impaired vocal cord mobility[3,4,8]; and larger tumor extent[3] (or tumor bulk[7]). We did not find these factors to be statistically significant and could be due to the fact that our patients were treated in a very homogeneous manner. Most patients were treated to a dose above 66 Gy, overall treatment time was kept short, larger fraction sizes were used, and there were minimum treatment delays and interruptions. Furthermore, most patients were treated with $6 \mathrm{MV}$ energy beams. It is unclear why heavy alcohol consumption during radiation was significant for local control. One reason could be due to the multi-organ effect of alcohol on the immune system and the bone marrow system during radiation. Another reason could be due to unknown biological mechanisms leading to reduced radiation damage within the cancer cells at the DNA level allowing cancer cells to become more radioresistant. Future work should address why concurrent heavy alcohol impacts local control in prospective studies.

Nearly all of our patients had baseline voice impairment with 73\% noting significant improvement and 8.5\% reported worsening after radiotherapy. Radiotherapy is considered an acceptable treatment option and has similar [16] to slightly superior [17] patient reported voice quality outcomes compared to $\mathrm{CO} 2$ laser excision, especially for T1 glottic carcinoma patients. However, radiotherapy is more costly [17] and provides no additional benefit in terms of differences in local control, laryngectomy free survival, or overall survival compared to C02 laser excision [17]. Radiation may be an option for those unwilling to undergo surgery or for those with multiply recurrent lesions after translaser oral excision. Future health policies will need to address cost-effective care for such patients through well controlled randomized trials. Patients with T2 disease often require more extensive surgical excision, thus the voice quality is better with radiotherapy and open partial larygenctomy may be more expensive [10].

There are several limitations. For one, our study is a single institutional retrospective review spanning over three decades. A direct comparison of radiotherapy with alternative treatment strategies such as transoral $\mathrm{CO} 2$ laser excision or an open partial laryngectomy is better made via a randomized controlled clinical trial. Another limitation includes availability of only subjective measures of patient reported and physician reported voice quality measures. Lastly, tumor volume and tumor volume dosimetry is better captured in modern 3D treatment techniques.

\section{Conclusion}

Definitive radiotherapy provides excellent LC and CSS for T1-T2a, N0 glottic SCC, with excellent voice preservation outcomes and minimal long term toxicity. T2b tumors have inferior outcomes, and alternative management strategies should be pursued. 


\section{Competing interest}

The authors declare that they have no competing interests.

\section{Authors' contribution}

MKK, SAK, and GKH participated in the study design and coordination, performed acquisition of data, and drafted the manuscript. CPR participated in the statistical data analysis. JPS was the treating physician over the 20 years and provided technical oversight to the project. All authors reviewed and approved the final manuscript. Our study was presented in an abstract form at the annual meeting of the American Society of Therapeutic Radiation Oncology in 2009 [18].

\section{Author details}

${ }^{1}$ Winship Cancer Center, Emory University, Atlanta, GA, USA. ${ }^{2}$ Taussig Cancer Institute, Cleveland Clinic, Cleveland, OH, USA.

Received: 9 August 2012 Accepted: 15 November 2012

Published: 19 November 2012

\section{References}

1. Nomiya T, Nemoto K, Wada H, Takai Y, Yamada S: Long-term results of radiotherapy for $\mathrm{T} 1 \mathrm{a}$ and $\mathrm{T} 1 \mathrm{bN} 0 \mathrm{M} 0$ glottic carcinoma. Laryngoscope 2008, 118:1417-1421.

2. Groome PA, O'Sullivan B, Mackillop WJ, Jackson LD, Schulze K, Irish JC, Warde PR, Schneider KM, Mackenzie RG, Hodson DI, et al: Compromised local control due to treatment interruptions and late treatment breaks in early glottic cancer: Population-based outcomes study supporting need for intensified treatment schedules. Int J Radiat Oncol Biol Phys 2006, 64:1002-1012.

3. Frata P, Cellai E, Magrini SM, Bonetti B, Vitali E, Tonoli S, Buglione M, Paiar F, Barca R, Fondelli S, et al: Radical radiotherapy for early glottic cancer: results in a series of 1087 patients from two Italian radiation oncology centers. II. The case of T2N0 disease. Int J Radiat Oncol Biol Phys 2005, 63:1387-1394.

4. Cho El, Sasaki CT, Haffty BG: Prognostic significance of pretreatment hemoglobin for local control and overall survival in T1-T2N0 larynx cancer treated with external beam radiotherapy. Int J Radiat Oncol Biol Phys 2004, 58:1135-1140.

5. Gowda RV, Henk JM, Mais KL, Sykes AJ, Swindell R, Slevin NJ: Three weeks radiotherapy for $\mathrm{T} 1$ glottic cancer: the Christie and Royal Marsden Hospital Experience. Radiother Oncol 2003, 68:105-111.

6. Garden AS, Forster K, Wong PF, Morrison WH, Schechter NR, Ang KK: Results of radiotherapy for T2N0 glottic carcinoma: does the "2" stand for twicedaily treatment? Int J Radiat Oncol Biol Phys 2003, 55:322-328.

7. Warde P, O'Sullivan B, Bristow RG, Panzarella T, Keane TJ, Gullane PJ, Witterick IP, Payne D, Liu FF, McLean M, et al: T1/T2 glottic cancer managed by external beam radiotherapy: the influence of pretreatment hemoglobin on local control. Int J Radiat Oncol Biol Phys 1998, 41:347-353.

8. Le QT, Fu KK, Kroll S, Ryu JK, Quivey JM, Meyler TS, Krieg RM, Phillips TL: Influence of fraction size, total dose, and overall time on local control of T1-T2 glottic carcinoma. Int J Radiat Oncol Biol Phys 1997, 39:115-126.

9. Burke LS, Greven KM, McGuirt WT, Case D, Hoen HM, Raben M: Definitive radiotherapy for early glottic carcinoma: prognostic factors and implications for treatment. Int J Radiat Oncol Biol Phys 1997, 38:1001-1006.

10. Chera BS, Amdur RJ, Morris CG, Kirwan JM, Mendenhall WM: T1N0 to T2N0 Squamous Cell Carcinoma of the Glottic Larynx Treated with Definitive Radiotherapy. Int J Radiat Oncol Biol Phys 2010, 78(2):461-466.

11. Greene FL, American Joint Committee on Cancer: AJCC cancer staging atlas. In Book AJCC cancer staging atlas (Editor ed.^eds.). City: Springer; 2006: ix-352. ix, $352 \mathrm{p}$

12. Reddy SP, Hong RL, Nagda S, Emami B: Effect of tumor bulk on local control and survival of patients with T1 glottic cancer: a 30-year experience. Int J Radiat Oncol Biol Phys 2007, 69:1389-1394.

13. Trotti AP, Emami T, Hammond B, Jones E, Morrison C, Sagar W, Ridge S, Fu J, Ang K, K K: A randomized trial of hyperfractionation versus standard fractionation in T2 squamous cell carcinoma of the vocal cord. Int J Radiat Oncol Biol Phys 2006, 66:S15.

14. Akimoto T, Nonaka T, Kitamoto $Y$, Ishikawa H, Ninomiya H, Chikamatsu K, Furuya N, Hayakawa K, Mitsuhashi N, Nakano T: Radiation therapy for T2N0 laryngeal cancer: A retrospective analysis for the impact of concurrent chemotherapy on local control. Int J Radiat Oncol Biol Phys 2006, 64:995-1001.

15. Nonoshita T, Shioyama Y, Nakamura K, Nakashima T, Ohga S, Yoshitake T, Ohnishi K, Terashima K, Asai K, Honda H: Concurrent chemoradiotherapy with S-1 for T2N0 glottic squamous cell carcinoma. J Radiat Res (Tokyo) 2010, 51:481-484.

16. Misono S, Merati AL: Are patient-reported voice outcomes better after surgery or after radiation for treatment of $\mathrm{T} 1$ glottic carcinoma? Laryngoscope 2011, 121:461-462.

17. Higgins KM: What treatment for early-stage glottic carcinoma among adult patients: $\mathrm{CO} 2$ endolaryngeal laser excision versus standard fractionated external beam radiation is superior in terms of cost utility? Laryngoscope 2011, 121:116-134.

18. Khan MK, Koyfman S, Hunter GH, Reddy S, Saxton JP: Outcome of Early Glottic (T1/T2) Treated with Radiotherapy at the Cleveland Clinic Foundation: A 20 Year Experience. Int J Radiat Oncol Biol Phys 2009, 75(3):S418-419.

doi:10.1186/1748-717X-7-193

Cite this article as: Khan et al: Definitive radiotherapy for early (T1-T2) Glottic Squamous cell carcinoma: a 20 year Cleveland clinic experience. Radiation Oncology 2012 7:193.

\section{Submit your next manuscript to BioMed Central and take full advantage of:}

- Convenient online submission

- Thorough peer review

- No space constraints or color figure charges

- Immediate publication on acceptance

- Inclusion in PubMed, CAS, Scopus and Google Scholar

- Research which is freely available for redistribution 